Review Article

\title{
Alanine Aminotransferase Levels are Associated with Cardiometabolic Risk Markers in Hispanic/Latino
} Farmworkers

\author{
Anas Raed ${ }^{1}$, Norman K. Pollock ${ }^{1}$, Jigar Bhagatwala ${ }^{1}$, Pamela Cromer ${ }^{2}$, Andrew \\ Mazzoli $^{3}$, Haidong Zhu ${ }^{1}$, Tricia Francisco', Jessica Bilz ${ }^{1}$, Rachel Azevedo ${ }^{1}$, Jan- \\ ice Clarke', Seung Su Lee', Aarthi Murugappan', Vishwajeeth Pasham', Deborah \\ Stewart' ${ }^{1}$, Yutong Dong', Ying Huang', Samip J. Parikh', Debbie Layman², and \\ Yanbin Dong *
}

${ }^{1}$ Georgia Prevention Institute, Medical College of Georgia, Augusta University, Building HS-1640, Augusta 30912, GA, USA

${ }^{2}$ College of Nursing, Augusta University, Augusta, GA, USA

${ }^{3}$ Respiratory Therapy Program, Augusta University, Augusta, GA, USA

\begin{abstract}
:
Introduction: Cardiovascular diseases (CVD) are major causes of mortality among U.S. Hispanic/Latino farmworkers. Since Hispanics/Latinos, in general, are twice as likely as non-Hispanic whites to have elevated alanine aminotransferase (ALT), a biomarker of suspected nonalcoholic fatty liver disease, it is vital to understand the CVD risk factor-ALT relationship in Hispanic/Latino farmworkers. This study investigated the elevated ALT status in Hispanic/Latino farmworkers and the relationships between ALT and CVD risk markers.

Methods: In 210 Hispanic/Latino farmworkers (48\% female; aged 35.2 \pm 9.2 years), fasting blood samples were measured for serum ALT, and elevated ALT was defined by $>43$ U/L. CVD risk markers were measured with standard methods and defined according to the definitions of metabolic syndrome.

Results: The overall prevalence for elevated ALT was 12.4\%. Significant linear upward trends across tertiles of serum ALT were observed for body mass index, waist circumference, fasting glucose, and triglycerides after adjusting for age and sex (all P-trend $<0.05$ ). Multinomial logistic regression, adjusting for age and sex, revealed that compared to individuals with the lowest ALT levels (tertile1), the adjusted odds ratios for overweight/obesity, prediabetes, elevated triglycerides, and metabolic syndrome were 3.2 (95\% CI:1.2-8.6), 3.7 (95\% CI:1.6-8.4), 3.0 (95\% CI:1.5-6.2), and 2.7 (95\% CI:1.3-5.6), respectively, for those in the highest ALT levels (tertile 3). No association was found between serum ALT and blood pressure or HDL-cholesterol.

Conclusions: Our findings provide evidence for the high prevalence of elevated ALT levels in Hispanic/Latino farmworkers and suggest that increased serum ALT is associated with multiple markers of CVD risk.
\end{abstract}

Keywords: Alanine aminotransferase; Cardiovascular disease; Hispanics; Farmworkers

\section{Introduction}

Occupational hazards among agricultural workers has been the primary focus of research, with minimal consideration given to chronic diseases (Agricultural Safety, NIOSH, 2016). Recently, there has been growing concern of increased cardiovascular disease (CVD) risk in the U.S. farmworker population (Arcury, et al. 2007; Emmi, et al. 2010; Castaneda, et al. 2015), of which Hispanics/Latinos make up the majority ( $>80 \%$ ) of this work force (Carroll, et al. 2005$)$.

Recent evidence has revealed that the U.S. Hispanic/Latino population is at high risk of CVD morbidity and mortality (Roger, V.L., et al. 2012). Risk factors and comorbidities of CVD, including obesity, type 2 diabetes, hypertension and hyperlipidemia, are especially elevated in Hispanic/Latino groups (Daviglus, M.L., et al. 2012) and may be attributed to the high risk of nonalcoholic fatty liver disease (NAFLD) in this population (Sherif ZA, et al. 2016).Hispanics/Latinos are at greater
Received date: January 31, 2018

Accepted date: February 23, 2018

Published date: February 28, 2018

*Corresponding author: Yanbin Dong, MD, $\mathrm{PhD}$, Georgia Prevention Institute, Medical College of Georgia, Augusta University, 1499 Walton way, HS-1755, Augusta, GA, 30901, Tel: 706-721-5014; E-mail: ydong@augusta.edu

Citation: Dong, Y., et al. Alanine Aminotransferase Levels are Associated with Cardiometabolic Risk Markers in Hispanic/Latino Farmworkers. (2018) J Environ Health Sci 4(1): 20- 25. 
risk of NAFLD (Ruhl, C.E., et al. 2003; Clark, J.M., et al. 2003; Browning J.D., et al. 2004; Lazo, M., et al. 2013; Smits, M.M., et al. 2013; Schneider, A.L., et al. 2014), and obesity is a key factor in the development of fatty liver disease (Pan, J.J., et al. 2014).The Hispanic/Latino population represented one-half of the U.S. population growth from 2000 to 2010, and they are estimated to constitute one-third of the U.S population within the next three decades; therefore, NAFLD may present a concern to the U.S. health care system (Ennis, S.R., et al. 2010).

The mild elevation of aminotransferase levels (less than five times the upper limit of normal) in asymptomatic patients could be attributed to NAFLD, alcohol consumption, or viral hepatitis (Oh RC and Hustead, T.R., 2011). NAFLD is the most common cause (80-90\%) of elevated aminotransferase levels in U.S. adults (Angulo, P., 2002; Ioannou, G.N., et al. 2006). Hence, ALT elevation is considered as a biomarker for suspected NAFLD (Bayard, M., et al. 2006).

Despite the increased prevalence rate of NAFLD in the general U.S. population of Hispanics/Latinos, it is unknown whether the NAFLD prevalence is greater in the Hispanic/Latino farmworker population. Given that CVD is a primary cause of mortality among U.S. Hispanic/Latino individuals combined with the fact that U.S. Hispanics/Latinos are twice as likely as non-Hispanic whites to have elevated alanine aminotransferase (ALT) levels, it is vital to understand relationships between CVD risk factors and elevated ALT in this population, particularly in farmworkers. Therefore, the purpose of this study was to determine the prevalence of elevated serum ALT levels in Hispanic/ Latino farmworkers. In addition, we determined relationships between serum ALT levels and markers of CVD risk.

\section{Methods}

\section{Participants}

The participants in this cross-sectional study were 210 Hispanic/Latino adults in a community outreach worksite project performed by the university as part of community partnership between Augusta University and Costa-Layman Farms to examine health risk concerns of Hispanic/Latino horticultural farmworkers. All Hispanic/Latino employees at the plant nursery in Trenton, South Carolina were invited to participate in this study. Participants with history of hypertension or diabetes were excluded from the study. Informed consent was obtained from all participants. The Institutional Review Board at Augusta University approved the study. All measurements were performed on-site at the plant nursery at Costa-Layman Farms between 2013 and 2015 .

\section{Anthropometry and blood pressure}

Height and weight were obtained according to standard procedures, using a wall-mounted stadiometer (Tanita Corporation of American, Arlington Heights, IL) and calibrated electronic scale (model CN2OL; Cardinal Detecto, Webb City, MO). Body mass index (BMI) was calculated using Center of disease Control and Prevention formula, weight $(\mathrm{kg}) /$ height $\left(\mathrm{m}^{2}\right)$ for which we used for body weight classification: $<25 \mathrm{~kg} / \mathrm{m}^{2}$ (normal weight), $25-29.9 \mathrm{~kg} / \mathrm{m}^{2}$ (overweight), or $\geq 30 \mathrm{~kg} / \mathrm{m}^{2}$ (obese) (Flegal, K.M., et al. 1998). A waist circumference (centimeters) was measured with minimal clothing at the level of umbilicus.
Elevated waist circumference was defined as $>102 \mathrm{~cm}$ for males, and $>88 \mathrm{~cm}$ for females (NCEP, 2002). After 5 minutes of rest, systolic (SBP) and diastolic blood pressures (DBP) were measured twice, each at least 1 minute apart, in sitting position using manual mercury sphygmomanometer. The averages of two measurements were reported and used for analyses. Prehypertension was defined as $\mathrm{SBP} \geq 120$ and $<140$ or $\mathrm{DBP} \geq 80$ and $<90$ $\mathrm{mmHg}$ based on the American Heart Association (AHA) definition (Chobanian, A.V., et al. 2003).

\section{Biochemical Measurements}

Venous blood was collected after an overnight fast, and all blood samples were centrifuged immediately and stored at $-80^{\circ} \mathrm{C}$ until required for analysis. Serum concentrations of glucose, glycosylated hemoglobin (HbA1C), lipid profile (high density lipoprotein-cholesterol [HDL- cholesterol] and triglycerides), and ALT were assessed by standard clinical laboratory methods at Premier Medical Laboratory Services (Greenville, SC). Fasting glucose was measured using hexokinase and glucose-6-phosphate dehydrogenase enzymatic method, while $\mathrm{HbA} 1 \mathrm{C}$ was determined based on turbidimetric inhibition immunoassay. Lipid parameters were measured by an enzymatic colorimetric method, using automated analyzer (Cobas c 311/501 and Cobas c 502) and Cobas enzymatic reagents. ALT was measured using the oxoglutarate reaction. Prediabetes was defined as fasting glucose $100-125 \mathrm{mg} / \mathrm{dL}$, or HbA1C 5.7-6.4\% based on the American Diabetes Association guidelines, (2012). Elevated triglycerides were defined as $\geq 150 \mathrm{mg} / \mathrm{dL}$, and low HDL-cholesterol was defined as $<40 \mathrm{mg} / \mathrm{dL}$ for males and $<50$ $\mathrm{mg} / \mathrm{dL}$ for females, respectively, based on National Cholesterol Education Program/Adult Treatment Panel III (NCEP/ATP III) guidelines (NCEP, 2002). The metabolic syndrome was defined as having three or more of the following cardiometabolic risk factors: elevated waist circumference, prehypertension, prediabetes, elevated triglycerides, low HDL-cholesterol (NCEP, 2002; American Diabetes Guidelines, 2012). Elevated ALT was defined based on the third National Health and Nutrition Examination Survey (NHANES) reference laboratory, which is higher than the upper limit of normal value as ALT $>43 \mathrm{U} / \mathrm{L}$ (Ruhl, C.E., et al. 2003; Ruhl, C.E, and Everhart, J.E., 2003).

\section{Statistical analyses}

We examined the ALT-cardiometabolic risk factor relationship by comparing the cardiometabolic risk factor variables across tertile groups of ALT (Tertile $1=6-15 \mathrm{U} / \mathrm{L}$, Tertile $2=16$ $24 \mathrm{U} / \mathrm{L}$, Tertile $3=25-169 \mathrm{U} / \mathrm{L})$.For comparison of the dependent variables (i.e., BMI, waist circumference, blood pressure, fasting glucose, $\mathrm{HbA1C}$, triglycerides, and HDL-cholesterol), an $F$ test was performed to test the assumption of homogeneity of regression slopes for the interactions between the independent variable (i.e., ALT tertile groups) and the covariates (age and sex). Because there were no interactions, ANCOVA with polynomial contrast was used to compare the dependent variables across ALT tertile groups after adjusting for the covariates. If the trend for difference in the dependent variable of interest across a tertile group of ALT was significant $(P<0.05)$, differences among individual tertiles, adjusted for multiple comparisons, were tested by using Tukey's honestly significant difference adjustment. Multinomial logistic regression was used to estimate 
odds ratios (OR) and 95\% confidence intervals $(\mathrm{CI})$ for the probability of outcome variables (i.e., overweight/obesity, elevated waist circumference, prehypertension, prediabetes, elevated triglycerides, low HDL-cholesterol, and metabolic syndrome) according to the predictor variable (i.e., tertiles of ALT) after adjusting for age and sex. All statistical analyses were conducted using SPSS software (version 23, IBM SPSS Statistics, Chicago, IL), and statistical significance was set at a value of $P<0.05$.

\section{Results}

Participant characteristics of the total sample are presented in Table 1. The sample was composed of 210 U.S. Hispanic/Latino adults with a nearly equal distribution of males and females with a mean age of approximately 35 years. In addition, over three-quarter of the participants were overweight or obese.

Table 1: Characteristics of the Hispanic/Latinofarmworkers participants

\begin{tabular}{|c|c|}
\hline Characteristic & Value \\
\hline $\mathrm{N}$ & 210 \\
\hline Age, y & $35.2 \pm 9.2$ \\
\hline Females, \% & 48.1 \\
\hline \multicolumn{2}{|l|}{ Anthropometrics } \\
\hline BMI, kg/m2 & $28.5 \pm 4.8$ \\
\hline Overweight/obesity status, $\%^{1}$ & 79.2 \\
\hline Waist circumference, $\mathrm{cm}$ & $92.8 \pm 10.4$ \\
\hline Elevated waist circumference, $\%^{2}$ & 38.4 \\
\hline \multicolumn{2}{|l|}{ Blood pressure } \\
\hline Systolic BP, mm Hg & $120.4 \pm 13.7$ \\
\hline Diastolic BP, mm Hg & $76.9 \pm 9.9$ \\
\hline Prehypertension, $\%^{3}$ & 41.5 \\
\hline \multicolumn{2}{|l|}{ Diabetes-related measures } \\
\hline Fasting glucose, mg/dL & $92.7 \pm 10.5$ \\
\hline HbA1c, $\%$ & $5.6 \pm 0.3$ \\
\hline Prediabetes, $\%^{4}$ & 29.5 \\
\hline \multicolumn{2}{|l|}{ Lipids } \\
\hline Triglycerides, mg/dL & $160.6 \pm 94.4$ \\
\hline Elevated triglycerides, $\%^{5}$ & 39.2 \\
\hline HDL-cholesterol, mg/dl & $47.7 \pm 12.2$ \\
\hline Low HDL-cholesterol, $\%^{6}$ & 43.5 \\
\hline Metabolic syndrome, $\%^{7}$ & 31.0 \\
\hline $\mathrm{ALT}, \mathrm{U} / \mathrm{L}$ & $24.5 \pm 19.5$ \\
\hline Elevated ALT, $\%{ }^{8}$ & 12.4 \\
\hline
\end{tabular}

${ }^{1} \mathrm{BMI}$ of 25 to 29.9 is considered overweight, while $\mathrm{BMI} \geq 30$ is considered obese; ${ }^{2}$ Defined as waist circumference $>102 \mathrm{~cm}$ for men and $>88 \mathrm{~cm}$ for women; ${ }^{3}$ Defined as systolic BP $120-139 \mathrm{~mm} \mathrm{Hg}$ and/or diastolic BP 80-89 mm Hg; ${ }^{4}$ Defined as a fasting blood glucose of 100$125 \mathrm{mg} / \mathrm{dl}$ and/or A1C test of 5.7-6.4\%; ${ }^{5}$ Defined as triglycerides $\geq 150$ $\mathrm{mg} / \mathrm{dL} ;{ }^{6}$ Defined as HDL cholesterol $<40 \mathrm{mg} / \mathrm{dL}$ for men and $<50 \mathrm{mg} /$ $\mathrm{dL}$ for women; ${ }^{7}$ Metabolic syndrome was defined as having three or more of the following cardiovascular risk factors: elevated waist circumference, prehypertension, prediabetes, elevated triglycerides, low HDL cholesterol; ${ }^{8}$ Defined as ALT levels $>43 \mathrm{U} / \mathrm{L}$.
When cardiometabolic risk variables were compared across tertiles of ALT adjusting for age and sex (Figure 1 and Supplemental Table 1), there were significant linear upward trends for BMI, waist circumference, fasting glucose, and triglycerides (all $P<0.05$ ). There were no differences in blood pressure, HbA1C, or HDL-cholesterol across tertiles of ALT (all $P>0.05)$
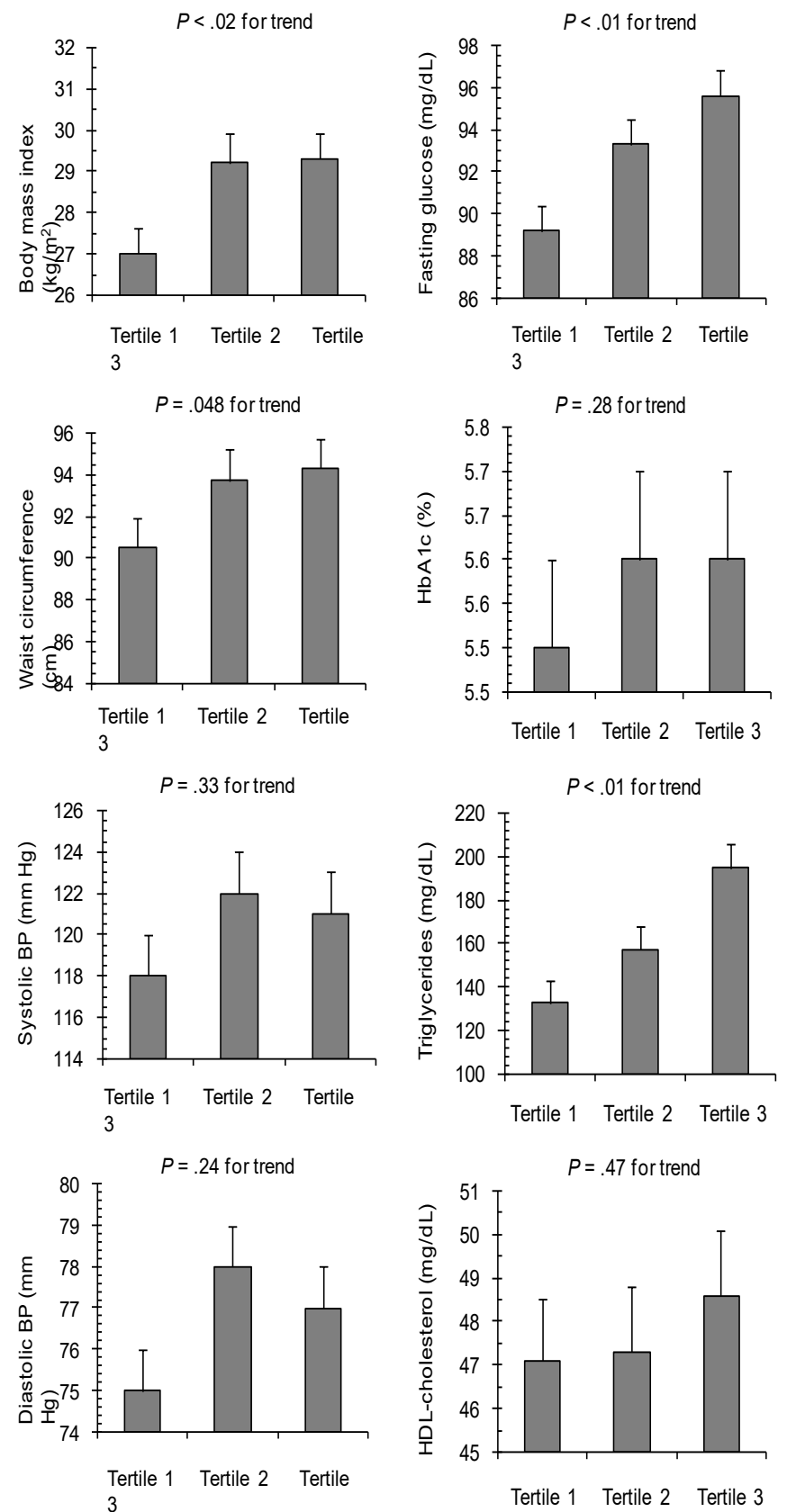

Figure 1: Cardiometabolic risk factors across tertiles of serum alanine aminotransferase levels in Hispanic/Latino farmworker participants. Outcome variables are adjusted means \pm SEM controlling for age an sex. Values in a row with superscripts without a common letter differ, $\mathrm{P}<0.05$.

The prevalence and adjusted odds ratios for the presence of overweight/obesity, elevated waist circumference, prehypertension, prediabetes, elevated triglycerides, low HDL-cholesterol, and metabolic syndrome across tertiles of ALT are presented in Table 2. There were a higher percentage of His- 
panic/Latino adults with overweight/obesity status, prediabetes, elevated triglycerides, and metabolic syndrome in the highest tertiles of ALT compared with the middle and lowest tertiles (all $P<0.05)$. Multinomial logistic regression, adjusting for age and sex, revealed that compared to individuals with the lowest ALT levels (tertile 1), the adjusted odds ratios for overweight/obesity, prediabetes, elevated triglycerides, and metabolic syndrome were significantly higher than for those in the highest ALT levels (tertile 3 ), respectively (all $P<0.03$ ) No association was observed between tertiles of ALT and elevated waist circumference, prehypertension, or low HDL-cholesterol (all $P>0.05$ ).

Table 2: Prevalence and adjusted odds ratios $(95 \% \mathrm{CI})$ for cardiometabolic risk factors across tertiles of serum ALT

\begin{tabular}{|c|c|c|c|c|}
\hline & \multicolumn{4}{|c|}{ Serum ALT, U/L ${ }^{a}$} \\
\hline & $\begin{array}{l}\text { Tertile } 1 \\
11 \mathrm{U} / \mathrm{L}(6- \\
15 \mathrm{U} / \mathrm{L})\end{array}$ & $\begin{array}{l}\text { Tertile } 2 \\
19 \text { U/L (16- } \\
24 \text { U/L) }\end{array}$ & \begin{tabular}{|l|} 
Tertile 3 \\
$43 \mathrm{U} / \mathrm{L}(25-$ \\
$169 \mathrm{U} / \mathrm{L})$
\end{tabular} & P-trend \\
\hline $\mathrm{n}$ & 73 & 66 & 71 & \\
\hline \multicolumn{5}{|c|}{ Overweight/obesity } \\
\hline Prevalence, $\%$ & 69.6 & 81.3 & 87.3 & 0.02 \\
\hline $\begin{array}{l}\text { Adjusted } \\
(95 \% \mathrm{CI})^{\mathrm{b}}\end{array}$ & 1.0 & $\begin{array}{l}1.9 \quad(0.7, \\
4.9)\end{array}$ & $\begin{array}{ll}3.2 & (1.2, \\
8.6)^{\mathrm{c}} & \end{array}$ & 0.02 \\
\hline \multicolumn{5}{|c|}{ Elevated waist circumference } \\
\hline Prevalence, $\%$ & 41.1 & 41.7 & 38.2 & 0.76 \\
\hline $\begin{array}{l}\text { Adjusted } \\
(95 \% \mathrm{CI})^{\mathrm{b}}\end{array}$ & 1.0 & $\begin{array}{l}1.3 \\
3.4)\end{array} \quad(0.5$, & $\begin{array}{l}1.3 \quad(0.5, \\
3.1)\end{array}$ & 0.62 \\
\hline \multicolumn{5}{|l|}{ Prehypertension } \\
\hline Prevalence, $\%$ & 46.4 & 64.6 & 58.2 & 0.21 \\
\hline $\begin{array}{l}\text { Adjusted } \\
(95 \% \mathrm{CI})^{\mathrm{b}}\end{array}$ & 1.0 & $\begin{array}{l}1.9 \quad(0.8, \\
4.4)\end{array}$ & $\begin{array}{l}1.3 \quad(0.6, \\
2.9)\end{array}$ & 0.56 \\
\hline \multicolumn{5}{|l|}{ Prediabetes } \\
\hline Prevalence, $\%$ & 16.4 & 33.3 & 39.4 & $<0.01$ \\
\hline $\begin{array}{l}\text { Adjusted } \\
(95 \% \mathrm{CI})^{\mathrm{b}}\end{array}$ & 1.0 & $\begin{array}{l}2.5 \\
5.7)^{\mathrm{c}}\end{array}$ & $\begin{array}{l}3.7 \\
8.4)^{\mathrm{c}}\end{array}$ & $<0.01$ \\
\hline \multicolumn{5}{|c|}{ Elevated triglycerides } \\
\hline Prevalence, $\%$ & 26.0 & 39.4 & 52.9 & $<0.01$ \\
\hline $\begin{array}{l}\text { Adjusted } \\
(95 \% \mathrm{CI})^{\mathrm{b}}\end{array}$ & 1.0 & $\begin{array}{l}1.8 \quad(0.9, \\
3.7)\end{array}$ & $\begin{array}{l}3.0 \quad(1.5, \\
6.2)^{\mathrm{c}}\end{array}$ & $<0.01$ \\
\hline \multicolumn{5}{|c|}{ Low HDL-cholesterol } \\
\hline Prevalence, $\%$ & 47.9 & 45.5 & 37.7 & 0.22 \\
\hline 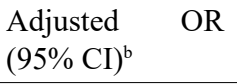 & 1.0 & $\begin{array}{l}1.0 \quad(0.5, \\
2.0)\end{array}$ & $\begin{array}{ll}0.8 & (0.4, \\
1.6) & \end{array}$ & 0.56 \\
\hline \multicolumn{5}{|c|}{ Metabolic syndrome } \\
\hline Prevalence, $\%$ & 23.3 & 37.9 & 40.8 & 0.03 \\
\hline $\begin{array}{l}\text { Adjusted } \\
(95 \% \mathrm{CI})^{\mathrm{b}}\end{array}$ & 1.0 & $\begin{array}{l}2.1 \quad(0.99, \\
4.4)\end{array}$ & $\begin{array}{l}2.7 \\
5.6)^{\mathrm{c}}\end{array}$ & 0.01 \\
\hline
\end{tabular}

${ }^{a}$ Values are mean (range) in a given tertile.

${ }^{\mathrm{b}}$ Data are adjusted for age and sex.

'Significantly different from the reference group, tertile $1(\mathrm{P}<0.05)$.

\section{Discussion}

To our knowledge, this is the first study to investigate the prevalence of elevated ALT, a biomarker for suspected NA-
FLD in Hispanic/Latino farmworkers. In addition, we are the first to report in this population that elevated ALT status is associated with multiple cardiometabolic abnormalities, including presence of overweight/obesity, prediabetes, elevated triglycerides, and metabolic syndrome.

The prevalence of elevated ALT in our sample of U.S. Hispanic/Latino farmworkers was substantially greater compared to Hispanics/Latinos from NHANES studies (Ruhl, C.E., et al. 2003; Clark, J.M., et al. 2003). The prevalence rate of suspected NAFLD was $12.4 \%$ in our study, whereas Ruhl, et al.(2003) and Clark, et al. (2003) reported suspected NAFLD prevalence rates of $8.4 \%$ and $9.9 \%$, respectively, based on data from the third NHANES (1988-1994).It is possible that the high prevalence of NAFLD in our sample of Hispanic/Latino farmworkers could be due to the high prevalence of overweight/obesity $(79.2 \%)$. When we compared tertiles of cardiometabolic risk factors across tertiles of ALT, we observed linear associations of ALT with BMI and waist circumference. This association could be attributed to multiple factors such as abnormalities in free fatty acids and glucose metabolism (Fabbrini, E., et al. 2010). In obese patients, the rate of releasing free fatty acids from adipose tissue and delivery to liver and skeletal muscle is increased, resulting concurrently increase in intrahepatic triglycerides and insulin resistance (Fabbrini, E., et al. 2010). Insulin resistance may be the link between adiposity and NAFLD (Fabbrini, E., et al. 2010). On the other hand, data from the Agricultural Workers Survey 2001-2002 have shown that U.S. farmworkers have more language barriers, lower education level, and less health insurance compared to non-farmworkers (Carroll, et al. 2005). This would suggest health risks in general are greater in the farmworker population.

In further analysis, we revealed that compared to individuals with the lowest ALT levels (tertile 1), the adjusted odds ratio for metabolic syndrome was 2.7 (95\% CI: 1.3-5.6) for those in the highest ALT levels (tertile 3). Several studies have reported that NAFLD is associated with metabolic syndrome (Marchesini, G., et al. 2005; Musso, G., et al. 2008). A study of Chinese people demonstrated that compared to people with the lowest ALT levels (quintile 1), the adjusted odds ratio for metabolic syndrome for both male and female were $4.6(95 \%)$ and $3.9(95 \%)$, respectively, for those in the highest ALT levels (quintile 5) (Lonardo, A., et al. 2015). It is possible that insulin resistance and elevated triglycerides in the presence of NAFLD may play roles in the pathophysiology of metabolic syndrome (Lonardo, A., et al. 2015). In fact, we found that the odds ratios for prediabetes and triglycerides were 3.7 (95\% CI: 1.6-8.4) and 3.0 (95\% CI: 1.5-6.2), respectively, for those in the highest ALT levels (tertile 3 ). The mechanism through which NAFLD is linked to diabetes may be explained by hepatic insulin resistance (Vanni E, et al. 2010). Hepatic intracellular diacylglycerols in lipid droplet could inhibit insulin signaling by activation of PKC, which also blocks insulin receptor kinase phosphorylation (Schindhelm, R.K., et al. 2007). The elevated triglycerides among NAFLD participants are explained by hepatic insulin resistance. One of insulin's actions is to restrain production of VLDL (Vanni E, et al. 2010). In the hepatic insulin resistance status among patients with NAFLD, insulin is not able to inhibit VLDL production, which leads to liver overproduction of TGrich VLDL (Baratta, F., et al. 2015). In addition, factors such 
Citation: Dong, Y., et al. Alanine Aminotransferase Levels are Associated with Cardiometabolic Risk Markers in Hispanic/Latino Farmworkers. (2018) J Environ Health Sci 4(1): 20- 25 .

as elevated uric acid, high fructose consumption, thyroid stimulating hormone, intestinal microbiota, and vitamin D deficiency may also be potential causes for progressing NAFLD to metabolic syndrome (Schindhelm, R.K., et al. 2007).

The study limitations should be acknowledged. Given that our study used cross-sectional data, we cannot be certain that elevated ALT has a direct effect on the cardiometabolic risk or vice versa. Second, almost $80 \%$ of individuals with NAFLD have normal ALT levels; therefore, the diagnosis of NAFLD via elevated ALT could underestimate the prevalence of NAFLD by imaging and biopsy (Browning, J.D., et al. 2004). Third, we did not collect a history of excessive alcohol consumption, hepatitis $\mathrm{B}$ or $\mathrm{C}$ infection, which might explain ALT elevation (Oh, R.C., and Hustead, T.R., 2011). However, study findings from NHANES 1988-1994, NHANES 1999-2002, and other studies reported that $80-90 \%$ of elevated ALT was NAFLD (Clark, J.M., et al. 2003; Angulo, P., 2002; Ioannou, G.N., et al. 2006), suggesting that our study findings are likely generalizable to many other settings. Fourth, given that participants were recruited from only one farm, the study findings may be generalized to Hispanic/Latino farmworkers. In addition, our disease definition was based on a single ALT measurement; however, we elected to be conservative and use the relatively high ALT cutoff $(>43$ $\mathrm{U} / \mathrm{L}$ ) for our analyses, as recommended in prior investigations (Ruhl, C.E., et al. 2003; Ruhl, C.E., and Everhart, J.E., 2003).

\section{Conclusions}

In conclusion, our data suggest that the U.S. Hispanic/ Latino farmworker population may be at greater risk for NAFLD than the general U.S. Hispanic/Latino population, a racial/ ethnic group already experiencing the highest rates of NAFLD compared to other racial/ethnic groups. Also, this study shows that Hispanic/Latino farmworkers with high ALT status have higher cardiometabolic risk factors, namely, overweight/obesity, prediabetes, elevated triglycerides, and metabolic syndrome. Additional research is needed in the Hispanic/Latino population, particularly in farmworkers, to assess long-term implications of elevated ALT levels with NAFLD and CVD.

\section{Acknowledgements and compliance with ethical standards}

The authors would like to thank the study participants and the research staff who made this study possible. The study was funded by the Institute of Preventive and Public Health at Augusta University. Prior to participation, all study participants gave written informed consent. The study was approved by the Institutional Review Board at Augusta University. This study was performed in accordance with the Helsinki Declaration of 1975 , as revised in 2000 . The study protocol has been reviewed and approved by the ethics/institutional review board at Augusta University.

Conflict of Interest: The authors report no conflicts of interest

Funding Support: The study was funded by Institute of Public and Preventive Health, Augusta University

Financial Disclosure: The authors have indicated that they have no financial relationships relevant to this article to disclose.
Abbreviations: AU: Augusta University; ALT: Alanine Aminotransferase; CVD: Cardiovascular Diseases; NAFLD: Nonalcoholic Fatty Liver Disease; BMI: Body Mass Index; SBP: Systolic Blood Pressure, DBP: Diastolic Blood Pressure; HbA1C: Glycosylated Hemoglobin; HDL-cholesterol: High Density Lipoprotein Cholesterol; NHANES: National Health and Nutrition Examination Survey.

Supplemental Table 1: Cardiometabolic risk factors across tertiles of serum ALT $^{1}$

\begin{tabular}{|l|l|l|l|l|}
\hline \multirow{2}{*}{} & \multicolumn{4}{ll}{ Serum ALT, U/L } \\
\cline { 2 - 5 } & $\begin{array}{l}\text { Tertile 1 11 } \\
\text { U/L } \\
\text { U/L) }\end{array}$ & $\begin{array}{l}\text { Tertile 2 19 } \\
\text { U/L (16-24 } \\
\text { U/L) }\end{array}$ & $\begin{array}{l}\text { Tertile 3 43 } \\
\text { U/L 25- } \\
169 \text { U/L) }\end{array}$ & P-trend \\
\hline $\mathrm{n}$ & 73 & 66 & 71 & \\
\hline BMI, kg/m & $27.0 \pm 0.6^{\mathrm{b}}$ & $29.2 \pm 0.7^{\mathrm{a}}$ & $29.3 \pm 0.6^{\mathrm{a}}$ & 0.02 \\
\hline $\begin{array}{l}\text { Waist circum- } \\
\text { ference, cm }\end{array}$ & $90.5 \pm 1.4^{\mathrm{b}}$ & $93.7 \pm 1.5^{\mathrm{a}}$ & $94.3 \pm 1.4^{\mathrm{a}}$ & 0.048 \\
\hline $\begin{array}{l}\text { Systolic BP, } \\
\text { mm Hg }\end{array}$ & $118 \pm 2$ & $122 \pm 2$ & $121 \pm 2$ & 0.33 \\
\hline $\begin{array}{l}\text { Diastolic BP, } \\
\text { mm Hg }\end{array}$ & $75 \pm 1$ & $78 \pm 1$ & $77 \pm 1$ & 0.24 \\
\hline $\begin{array}{l}\text { Fasting glu- } \\
\text { cose, mg/dL }\end{array}$ & $89.4 \pm 1.2^{\mathrm{b}}$ & $93.3 \pm 1.2^{\mathrm{a}}$ & $95.6 \pm 1.2^{\mathrm{a}}$ & $<0.01$ \\
\hline HbA1c, \% & $5.5 \pm 0.1$ & $5.6 \pm 0.1$ & $5.6 \pm 0.1$ & 0.28 \\
\hline $\begin{array}{l}\text { Triglycerides, } \\
\text { mg/dL }\end{array}$ & $132.5 \pm 10.6^{\mathrm{b}}$ & 157.0 & 194.5 & $<0.01$ \\
\hline $\begin{array}{l}\text { HDL-choles- } \\
\text { terol, mg/dl }\end{array}$ & $47.1 \pm 1.4$ & $47.3 \pm 1.5^{\mathrm{b}}$ & $48.6 \pm 1.5$ & 0.47 \\
\hline
\end{tabular}

Abbreviations: ALT; alanine aminotransferase; BMI, body mass index; BP, blood pressure; HbA1c, hemoglobin A1c.

${ }^{1}$ Values are mean \pm SEM adjusted for age and sex. Values in a row with superscripts without a common letter differ, $\mathrm{P}<0.05$.

\section{References}

-Agricultural Safety. Centers for Disease Control and Prevention, National Institute for Occupational Safety and Health (NIOSH) Workplace Safety and Health Topic. 2016 PubMed | CrossRef | Others

-American Diabetes Association. Diagnosis and classification of diabetes mellitus. (2012) Diabetes Care 35 (Suppl 1): S64-S71. PubMed | CrossRef | Others

-Angulo, P. Nonalcoholic fatty liver disease. (2002) N Engl J Med 346 (16): 1221-1231.

PubMed |CrossRef | Others

-Arcury, T.A., Quandt, S.A. Delivery of health services to migrant and seasonal farmworkers. (2007) Annu Rev Public Health 28: 345-363. PubMed |CrossRef|Others

-Baratta, F., Pastori, D., Polimeni, L., et al. Does Lysosomial Acid Lipase Reduction Play a Role in Adult Non-Alcoholic Fatty Liver Disease? (2015) Int J Mol Sci 16(12): 28014-28021. PubMed |CrossRef | Others

-Bayard, M., Holt, J., Boroughs, E. Nonalcoholic fatty liver disease. (2006) Am Fam Physician 73(11): 1961-1968. PubMed | CrossRef | Others

-Browning, J.D., Szczepaniak, L.S., Dobbins, R., et al. Prevalence of hepatic steatosis in an urban population in the United States: impact of ethnicity. (2004) Hepatology 40(6): 1387-1395.

PubMed |CrossRef | Others 
-Castaneda, S.F., Rosenbaum, R.P., Holscher, J.T., et al. Cardiovascular disease risk factors among Latino migrant and seasonal farmworkers. (2015) J Agromedicine 20(2): 95-104. PubMed |CrossRef| Others

-Clark, J.M., Brancati, F.L., Diehl, A.M. The prevalence and etiology of elevated aminotransferase levels in the United States. (2003) Am J Gastroenterol 98(5): 960-967. PubMed | CrossRef | Others

-Chobanian, A.V., Bakris, G.L., Black, H.R., et al. Seventh report of the Joint National Committee on Prevention, Detection, Evaluation, and Treatment of High Blood Pressure. (2003) Hypertension 42(6):1206-1252.

PubMed | CrossRef | Others

-Carroll, D., Samardick, R.M., Bernard, S., et al. Findings from the National Agricultural Workers Survey (NAWS) 2001-2002. (2005) A Demographic and Employment Profile of United States Farm Workers PubMed |CrossRef| Others

-Daviglus, M.L., Talavera, G.A., Aviles-Santa, M.L., et al. Prevalence of major cardiovascular risk factors and cardiovascular diseases among Hispanic/Latino individuals of diverse backgrounds in the United States. (2012) JAMA 308(17): 1775-1784. PubMed |CrossRef| Others

-Emmi, K.E., Jurkowski, J.M., Codru, N., et al. Assessing the health of migrant and seasonal farmworkers in New York State: statewide data 2003-2005. (2010) J Health Care Poor Underserved 21(2): 448-463. PubMed |CrossRef|Others

-Ennis, S.R., Rios-Vargas, M., Albert, N.G. The Hispanic population: 2010. 2010 Census Briefs. (2011) U.S PubMed | CrossRef $\mid$ Others

-Fabbrini, E., Sullivan, S., Klein, S. Obesity and nonalcoholic fatty liver disease: biochemical, metabolic, and clinical implications. (2010) Hepatology 51(2): 679-689. PubMed | CrossRef| Others

-Flegal, K.M., Carroll, M.D., Kuczmarski, R.J., et al. Overweight and obesity in the United States: prevalence and trends, 1960-1994. (1998) Int J Obes Relat Metab Disord 22(1): 39-47. PubMed | CrossRef | Others

-Ioannou, G.N., Boyko, E.J., Lee, S.P. The prevalence and predictors of elevated serum aminotransferase activity in the United States in 1999-2002. (2006) Am J Gastroenterol 101(1): 76-82. PubMed | CrossRef| Others

-Lazo, M., Hernaez, R., Eberhardt, M.S., et al. Prevalence of nonalcoholic fatty liver disease in the United States: the Third National Health and Nutrition Examination Survey, 1988-1994. (2013) Am J Epidemiol 178(1): 38-45. PubMed | CrossRef | Others

-Lonardo, A., Ballestri, S., Marchesini, G., et al. Nonalcoholic fatty liver disease: a precursor of the metabolic syndrome. (2015) Dig Liver Dis 47(3): 181-190. PubMed | CrossRef| Others

-Marchesini, G., Avagnina, S., Barantani, E.G., et al. Aminotransferase and gamma-glutamyltranspeptidase levels in obesity are associated with insulin resistance and the metabolic syndrome. (2005) J Endocrinol Invest 28(4): 333-339. PubMed | CrossRef| Others

-Musso, G., Gambino, R., Bo, S., et al. Should nonalcoholic fatty liver disease be included in the definition of metabolic syndrome - A cross-sectional comparison with Adult Treatment Panel III criteria in nonobese nondiabetic subjects. (2008) Diabetes Care 31(3): 562568. PubMed | CrossRef | Others

-National Cholesterol Education Program (NCEP) Expert Panel on Detection, Evaluation and Treatment of High Blood Cholesterol in Adults (Adult Treatment Panel III). Third Report of the National Cholesterol Education Program (NCEP) Expert Panel on Detection,
Evaluation, and Treatment of High Blood Cholesterol in Adults (Adult Treatment Panel III) final report. (2002) Circulation 106(25): 3143-3421.

PubMed | CrossRef | Others

-Oh, R.C., Hustead, T.R. Causes and evaluation of mildly elevated liver transaminase levels. (2011) Am Fam Physician 84(9): 1003-1008. PubMed | CrossRef $\mid$ Others

-Pan, J.J., Fallon, M.B. Gender and racial differences in nonalcoholic fatty liver disease. (2014) World J Hepatol 6(5): 274-283. PubMed | CrossRef | Others

-Roger, V.L., Go, A.S., Lloyd-Jones, D.M., et al. Executive summary: heart disease and stroke statistics--2012 update: a report from the American Heart Association. (2012) Circulation 125(1):188-197. PubMed | CrossRef| Others

-Ruhl, C.E., Everhart, J.E. Determinants of the association of overweight with elevated serum alanine aminotransferase activity in the United States. (2003) Gastroenterology 124(1): 71-79. PubMed | CrossRef| Others

-Ruhl, C.E., Everhart, J.E. Relation of elevated serum alanine aminotransferase activity with iron and antioxidant levels in the United States. (2003) Gastroenterology 124(7): 1821-1829. PubMed | CrossRef|Others

-Schneider, A.L., Lazo, M., Selvin, E., et al. Racial differences in nonalcoholic fatty liver disease in the U.S. population. (2014) Obesity (Silver Spring) 22(1): 292-299. PubMed | CrossRef | Others

-Schindhelm, R.K., Diamant, M., Heine, R.J. Nonalcoholic fatty liver disease and cardiovascular disease risk. (2007) Current Diab Reports 7(3): 181-187. PubMed | CrossRef $\mid$ Others

-Sherif, Z.A., Saeed, A., Ghavimi, S., et al. Global Epidemiology of Nonalcoholic Fatty Liver Disease and Perspectives on US Minority Populations. (2016) Dig Dis Sci 61(5): 1214-1225. PubMed | CrossRef|Others

-Smits, M.M., Ioannou, G.N., Boyko, E.J., et al. Non-alcoholic fatty liver disease as an independent manifestation of the metabolic syndrome: results of a US national survey in three ethnic groups. (2013) J Gastroenterol Hepatol 28(4): 664-670. PubMed | CrossRef| Others

-Vanni, E., Bugianesi, E., Kotronen, A., et al. From the metabolic syndrome to NAFLD or vice versa? (2010) Dig Liver Dis 42(5): 320-330.

PubMed | CrossRef | Others

Submit your manuscript to Ommega Publishers and we will help you at every step:

- We accept pre-submission inquiries

- Our selector tool helps you to find the most relevant journal

- We provide round the clock customer support

- Convenient online submission

- Thorough peer review

- Inclusion in all major indexing services

- Maximum visibility for your research

Submit your manuscript at

OMMEgA Publishers https://www.ommegaonline.org/submit-manuscript 